\title{
Enhancing Oxidative Stability and Shelf Life of Cooking Oils Using Citrus Peel Extracts
}

\author{
Mohamed Gamal ${ }^{1}$, Sobhy El Sohaimy ${ }^{1}$, Mohammed Youssef $^{2}$, Dalal Asker ${ }^{3}$, and Tarek \\ Awad $^{3}$ \\ ${ }^{1}$ City of Scientific Research and Technological Applications \\ ${ }^{2}$ Alexandria University \\ ${ }^{3}$ University of Toronto
}

June 8, 2020

\begin{abstract}
Citrus peels are nonedible by-products that are often discarded. This work explores the bioactive compounds extracted from the peels of 4 local citrus fruits, their antioxidant and antimicrobial activities and applicability as natural antioxidants for vegetable oils. Total soluble phenols and total flavonoids were extracted from orange, lemon, tangerine and grapefruit peels using various solvents. Orange peel methanol extract produced the highest yield ( $\sim 16 \mathrm{~g} / 100 \mathrm{~g})$, however using ethanol maximized the concentration of total phenols $(\sim 345 \mathrm{mg}$ Gallic acid equivalents/100g dry weight) as well as total flavonoids ( $~ 80 \mathrm{mg}$ catechol equivalents/100g). In general, extracts with high total phenolic contents exhibited high antioxidant capacities. The orange peel ethanol extract showed the highest DPPH and ABTS values while its methanol extract exhibited the highest hydroxyl radical scavenging value. In addition, all citrus peel extracts possessed high antimicrobial activity against several food-borne Gram-negative and Gram-positive pathogenic bacteria and fungi. The composition of polyphenolic compounds in orange peel extracts analyzed by ultra-performance liquid chromatography combined with mass spectrometry (UPLC-ESI-MS/MS) revealed the presence of 22 and 32 compounds in the aqueous and ethanolic extracts, respectively. The predominant compounds were narirutin, naringin, hesperetin-7-O-rutinoside naringenin, quinic acid, hesperetin, datiscetin-3-O-rutinoside and sakuranetin. Importantly, incorporation of orange peel extract into vegetable oils greatly enhanced their oxidative stability compared to a synthetic antioxidant (BHT). Overall results support the potential of citrus peels as natural antioxidants and antimicrobials for enhancing the shelf life, storage stability and safety of food oils.
\end{abstract}

\section{Hosted file}

Citrus peels_manuscript_JAOCS_Awad.doc available at https://authorea.com/users/331198/ articles/457895-enhancing-oxidative-stability-and-shelf-life-of-cooking-oils-usingcitrus-peel-extracts

\section{Hosted file}

Figures_JAOCS.docx available at https://authorea.com/users/331198/articles/457895-enhancingoxidative-stability-and-shelf-life-of-cooking-oils-using-citrus-peel-extracts 